\title{
Factors Contributing to the Success of Benchmarking: A South African Perspective
}

\author{
J S Human \\ Momentum Group Limited, Centurion \\ M Shotter \\ School of Accountancy, University of Pretoria
}

\section{ABSTRACT}

This study aims to identify the factors that have an influence on the success of benchmarking projects, and finds that listed South African manufacturing companies achieve a high degree of success with their benchmarking projects. The key success factors are a cost-benefit analysis and the formulation of an implementation plan during the planning stage of the process. Other factors include limitation of the scope and length of the project, an optimum number of four partners, the selection of partners of similar size and the inclusion of partners from other industries. It was also found that the compliance with a code of conduct by all the partners and the consideration of ethical and legal aspects are essential elements of success.

JEL M 21

\section{INTRODUCTION}

Benchmarking can be described in a number of ways. One of the most basic definitions would be the practice of being humble enough to admit that other organisations perform better at something, whilst at the same time being wise enough to learn how to match and preferably surpass identified performance levels (Andersen \& Pettersen, 1996: 3). Some of the elements to be found in most definitions include the investigation of one's own products, processes and strategies, comparison with the best performance of other organisations, and improved performance due to the implementation of identified improvements. For the purpose of this article we adopt the definition of Elnathan, Lin and Young (1996: 40), namely that benchmarking is a process by which an organisation targets key areas for improvement, studies the best practice of others and implements processes and systems to enhance its own performance.

The outward orientation of benchmarking distinguishes it from performance measurement, which is the comparison of performance with internally 
determined norms (Thor, 1995: 3). Whereas performance measurement contributes to the evaluation of the effectiveness of an organisation, benchmarking evaluates its competitiveness. However, performance measurement is a prerequisite for benchmarking as it provides the norms against which the performance of other organisations are measured in order to determine performance gaps.

There are several forms of benchmarking and classification normally depends on the approach to a project (Maxon \& Trefty, 1997: 7). Where benchmarking is approached in terms of the choice of partners, the project can be classified into internal, external and competitive benchmarking. If the topic is the focus of the project, benchmarking can be classified as product, process or functional, best practice or generic and strategic benchmarking. Finally, if classified according to the method followed, benchmarking can be categorised as desk research, interviews, benchmarking databases, consortium benchmarking and partnership benchmarking.

\section{RESEARCH PROBLEM}

Although the benefits of benchmarking are far-reaching, it is generally an expensive process. The time spent by managers, employees and external benchmarking consultants on a project are only some of its direct costs. Frequently the results of a benchmarking project also require that employees undergo a total cultural change (Elnathan et al., 1996: 49).

There are several possible pitfalls when conducting a benchmarking process. Where a project is abandoned due to a lack of support by senior management, the initial investment is wasted. If a project is drawn out, the information collected might become obsolete and irrelevant. Choices of benchmarking partners and methods of collecting information are also factors that can influence the success of a project (Elnathan et al., 1996: 42-48, Lincoln \& Price, 1996: 33-35).

The aim of this study is to identify the factors that contribute to the success of benchmarking, bearing in mind that it is a relatively new practice, that it is expensive and that there are several factors that might cause a benchmarking project to fail.

The factors that contributed to the success of benchmarking in other countries are identified by means of an extensive literature review. The purpose of the empirical work is to establish which of these factors that were identified in 
overseas studies are also significant contributors to the success of benchmarking projects in South Africa.

\section{FACTORS CONTRIBUTING TO THE SUCCESS OF BENCHMARKING}

A literature review of case studies and surveys conducted in Europe, the USA and Japan indicates that a number of factors have contributed to the success of benchmarking projects. The Benchmarking Portfolio (TBP) (1997: 15) ascribes the success of companies like Xerox, Motorola and Hewlett-Packard to these factors as described in 3.1 to 3.17 .

\subsection{Integral part of corporate strategy}

An organisation should formalise and understand its own strategy before embarking on a benchmarking project, in order to avoid the implementation of measures that are not in accordance with its overall strategy. For benchmarking to be effective, it should form part of a regular management agenda and organisational strategy (Bendell, Boulter \& Kelly, 1993: 198). A strategic benchmarking project can provide insight into the strategy of benchmarking partners, thus enabling the company that initiated the project to formulate its own (Miller, De Meyer \& Nakane, 1992: 22).

Companies should be aware of the areas in which they have a competitive advantage and those in which their performance is unsatisfactory, in order to direct benchmarking projects to where change will be most beneficial. Japanese companies, in particular, employ benchmarking to improve their competitive advantage and to reduce the performance gap where they do not perform as well as their competitors (Zairi \& Leonard, 1994: 190).

\subsection{Involvement of senior management}

It is the responsibility of senior management to create a culture within an organisation where benchmarking forms an integral part of its activities. They should set targets that would result in improved performance, communicate the results of benchmarking projects throughout the company and form networks within and outside the company that may be used for collecting information (TBP, 1997: 17).

The involvement of senior management provides the attribute of transparency to a project (Zairi \& Leonard, 1994: 190). The public image of a company can be destroyed if certain of its actions are labelled as industrial espionage. According 
to Bogan and English (1994: 69), involvement of senior management will also raise the motivation of the team members of the project, since this should assure that sufficient resources will be allocated to the project and that it will not be abandoned after months of hard work.

Involvement by senior management will also increase the probability that the project forms an integral part of the corporate strategy (TBP, 1997: 16). If unsupervised, middle management might undertake a benchmarking project that results in changes beneficial to a certain department but detrimental to others and the company as a whole. It is the responsibility of senior management to prevent this from happening.

\subsection{Focus on critical success factors}

Critical success factors are those few key areas where things "must go right for the company to flourish" (Lincoln \& Price, 1996: 34). These factors will differ amongst companies and include customers, competitive advantages, financial stability and strategy. To stress these factors during a benchmarking process, will ensure that information is collected in areas with the greatest influence on the company's success. Critical success factors should be borne in mind when selecting the object of the benchmarking process, in the development of key performance measures and in identifying benchmarking partners. It should also be considered in the development of a survey questionnaire and the preparation of the final analysis and recommendations.

Benchmarking should only be conducted if it can add value to the decision making process (Spendolini, 1992: 68). Due to the fact that it is a costly process, companies that follow a structured approach to problem solving should restrict benchmarking to identify solutions for critical problems. It should not be employed to resolve routine obstacles.

\subsection{Performing a cost-benefit analysis}

A benchmarking project should only be undertaken if the expected advantages outweigh the expected costs (TBP, 1997: 23). Although it is often difficult to express increased client satisfaction, productivity, market share and quality in monetary terms, the estimated value of these advantages should be compared to the best estimate of the costs of the project.

\subsection{The length of the project}

According to Lincoln and Price (1996: 33) it is not uncommon for a benchmarking project to last from nine to twelve months. Team members might leave a company or be transferred to another department during such a long 
period, whilst changes in m.nagement can lead to the abandonment of a project after months of hard work. Furthermore, circumstances might change within the area that is the focus of the project, thus causing recommendations to become obsolete. Several steps can be taken to ensure that the length of the project is limited to an acceptable time span. Sufficient human resources should be allocated to the proiect. Team members should be relieved from some of their responsibilities to enable :'iem to devote sufficient time to the project (Lincoln \& Price, 1996: 33), and external consultants may be appointed to facilitate the project, conduct research and approach benchmarking partners. A culture of continuous improvement will ensure that processes are continuously inspected and documented, that client expectations are monitored and actual performance is measured against expected performance on a regular basis (Lincoln \& Price, 1996: 34). These factors can contribute to limiting the scope of projects to a manageable size.

\subsection{The subject of the project}

When considering a suitable topic for a benchmarking project, two aspects should be borne in mind, namely the purpose and the extent of the project. With regard to the purpose, a selection of a subject that is widely known to be a problem within the organisation, normally results in a successful project (Andersen \& Pettersen, 1996: 139). The benchmarking project will be associated with the answer to a specific difficulty, which can increase the support for benchmarking within an organisation.

Another consideration is the extent of the project. According to Elnathan et al. (1996: 44), the motivation of a benchmarking team suffers when trying to achieve too much with a single assignment. Lincoln and Price (1996: 34) recommend that one should either choose a broad-and-shallow approach or a narrow-and-deep approach. This means that one should either collect general information on a few areas or detailed information on a single area. When trying to collect detailed information on a few areas, the project will be drawn out too long. The suggested procedure is to initially pursue a broad-and-shallow approach, followed by a narrow-and-deep approach in a next project.

\subsection{Studying the company's own product or process}

Knowledge of the products and processes of one's own company forms the basis for studying those of other companies (TBP, 1997: 32). If a benchmarking team is unfamiliar with their own products and processes, it will be impossible to determine a performance gap and identify opportunities for improvement. It would then also be difficult for a firm to answer any questions by its external partners regarding its own products and processes. Karlöf and Östblom (1993: 
58) concur and suggest that internal benchmarking should be carried out prior to external benchmarking, in order to provide the team with the opportunity to practice various techniques and methods internally, before launching a project with external partners.

\subsection{Previous benchmarking experience}

The likelihood of lower costs and greater success with benchmarking projects increases as an organisation acquires benchmarking experience (Elnathan et al., 1996: 44). Karlöf and Östblom (1993: 70) suggest that project teams should always include employees with benchmarking experience, in order to increase the level of knowledge within the team and to reduce total training costs. Companies with prior benchmarking experience will normally be able to make more informed decisions on the subject matter of the project, the most effective manner of data collection and choice of benchmarking partners (Elnathan et al., 1996: 43). Normally, organisations with benchmarking experience will also be contacted more frequently by other companies who would like to become involved in benchmarking projects.

\subsection{The compilation of a benchmarking team}

When selecting a team, the required areas of specialisation for the project, the time needed from team members as well as the optimum combination of internal employees and external consultants should be considered. By combining the areas of specialisation of a group of individuals, the project can be completed more efficiently. Team members should be able to spend at least 25 per cent of their time on the project, whilst the team leader should devote a minimum of 50 per cent of his/her time to the task (TBP, 1997: 28).

The use of external, professional benchmarking consultants should also be considered (Karlöf \& Östblom, 1993: 69), since they normally have useful contacts with a number of potential partners and their experience in project management should be an asset. Consultants can play an important role in competitive benchmarking projects, where results may be provided in a blind format, thus avoiding sensitive information being directly exchanged between competitors (TBP, 1997: 31).

\subsection{Training of team members}

A perception exists that benchmarking does not require any special knowledge, resulting in organisations being unprepared for the projects (Bogan \& English, 1994: 73). In fact, the success of benchmarking largely depends on the amount of training that the team members receive in the benchmarking techniaues. 
process, philosophy and method. There are two schools of thought in respect of benchmarking training (TBP, 1997: 31). The first school believes in the socalled Xerox approach that all the employees should be trained in benchmarking, whilst the second school believes that all employees should be informed about benchmarking, but that only team members should be trained extensively. The second approach is probably more practical.

\subsection{The selection of benchmarking partners}

When a company decides to conduct external benchmarking, there are a number of factors regarding partners that might influence the success of the project. These factors include the size and number of the partners as well as their industry and geographical location. Further aspects that should be considered are the position that the partners occupy in their respective industries and the degree of trust between the organisation and the partner(s) (Elnathan et al., 1996: 47).

There is no single best-in-class company, nor is there a list that contains a bestin-class company in each functional area (Lincoln \& Price, 1996: 35). It is important that the organisation that initiates the project selects partners that are suitable to their unique circumstances. Furthermore, partners should not be limited to the organisation's geographical location, since technology today enables companies to conduct benchmarking projects across the globe (TBP, 1997: 34).

In order to facilitate a comparison of information, adjustments can be made to compensate for differences in products, processes, market conditions, cost structures, the age and size of companies as well as differences in regulations (Karlöf \& Östblom, 1993: 153). However, after the data has been normalised to compensate for differences, any remaining performance gap should be accepted and addressed (Andersen \& Pettersen, 1996: 73).

\subsection{The availability of resources}

The resources required to successfully conduct a benchmarking project, are mostly employee time, finance and equipment (Bogan \& English, 1994: 80). In companies with an established culture of continuous improvement, the resources are normally forthcoming when the existence of a performance gap can be proved (Zairi \& Leonard, 1994: 192). Resources allocated to a benchmarking project should be closely monitored by means of a budget, and care should be taken to ensure that they are optimally employed. The effective use of computer equipment, in particular, can substantially decrease the total costs of the project (Bogan \& English, 1994: 76). 


\subsection{The methods and techniques of data collection}

Andersen and Pettersen (1996: 56) distinguish between methods and techniques of data collection. Methods of data collection refer to the manner in which a partner is contacted, for example by post, telephone, personal interview or teleconference, whilst techniques include questionnaires, interviews, direct observation and reversed product design. The last-mentioned technique describes a situation where the product of a competitor is purchased and dismantled, in order to get a better understanding of their manufacturing process. When deciding upon a suitable method and instrument for data collection, the planned time span, budget, availability of personnel, past experience, complexity of the information and the skills required to conduct the specific technique of collection should all be considered (Andersen \& Pettersen, 1996: 56, Zairi \& Leonard, 1994: 73).

Regardless of the method of data collection, a written questionnaire should always be prepared, since it provides guidance to the information required and ensures that all the relevant information is collected (TBP, 1997: 35). Background information on the company initiating the project, as well as the objectives of the project, should be forwarded to partners prior to commencing with data collection (Spendolini, 1992: 157) and the questionnaire should be tested internally before contacting a partner. Only questions that the initiating organisation would also be prepared to answer should be included (Bogan \& English, 1994: 98).

The questionnaire should be limited to a reasonable length and questions should be asked in a logical sequence, with general questions first followed by specific questions (Karlöf \& Östblom, 1993: 136). It is important that a balance is maintained between quantitative and qualitative information, and questions based on ratios are preferred to absolute values, since this increases the probability of maintaining confidentiality.

\subsection{The development of a culture of learning}

Benchmarking flourishes in an organisation with a culture of learning, since employees are encouraged to be outward looking, compare their own performance with those of others and to make recommendations for improvements (Bogan \& English, 1994: 77). In a culture of learning, employees are encouraged to think holistically, systematically and creatively, and to share information across functional borders. The objective is to develop rather than to control employee potential, and managers are seen as advisers and mentors. Normally there are no job descriptions in such an organisation, in order to encourage employees to experiment and to take on responsibility on their own 
initiative (Mansell, 1997: 62). This creates the ideal climate for implementing the improvements suggested by a benchmarking project, since employees are part of an environment where change is encouraged (Mansell, 1997: 63).

\subsection{Ethical and legal aspects of benchmarking}

Benchmarking involves an outward looking stance on the practices of other companies, with potentially negative ethical and legal consequences (Scheffler, 1997: 167). From a legal point of view, claims can be lodged against a company, whilst unethical behaviour can cause irreparable damage to a company's image. The International Benchmarking Clearinghouse in conjunction with the Benchmarking Council of the Strategic Planning Institute, developed a benchmarking code of conduct (Scheffler, 1997: 167). If a company adheres to this code, obtains necessary legal advice and treats its benchmarking partners in the same way as it expects to be treated, it should not encounter any difficulties regarding the ethical and legal aspects of benchmarking.

\subsection{Conducting a pilot run}

It is especially important for companies undertaking benchmarking for the first time, not to contact benchmarking partners directly after the preparatory work has been completed (TBP, 1997: 32). Inexperienced team members may not know how to phrase questions correctly and how to interpret the response of the person being questioned, and may also have insufficient knowledge of the subject of the project. A pilot run can overcome most of these difficulties and also provides an opportunity to identify and correct problems with the questionnaire.

\subsection{Communication and implementation of improvements}

To ensure that the greatest number of people are informed about the outcome of a project, a database should be created with all the relevant information and with easy access for all employees (Karlöf \& Östblom, 1993: 178). A formal report should be compiled and stored in the database.

According to Spendolini (1992: 181) a company like DEC only conducts a benchmarking project after a specific decision has been taken that change is needed, whereupon there is normally little resistance to the implementation of improvements. A plan of implementation should be formulated which covers the sequence of activities involved, persons responsible as well as the budget and timetable for the implementation of improvements (Karlö \& Östblom, 1993: 176). 


\section{RESEARCH METHOD USED IN EMPIRICAL WORK}

The aim of the empirical research was to establish the factors that contribute to the success of benchmarking in South Africa. The research instrument consisted of a questionnaire, with a question on the success of the most recently completed benchmarking project representing the dependent variable, whilst the questions on the extent to which each factor contributed to the success of that project represent the independent variables (Human, 2000: 127). The questionnaire was circulated among 178 manufacturing companies listed on the Johannesburg Stock Exchange during March to August 1999. Only manufacturing companies were included in the population in order to limit it to a manageable size, and also because the majority of the examples mentioned in the literature are manufacturing companies (Human, 2000: 119). The focus on listed companies is based on the finding by Randall (1995: 94) that there is a greater likelihood that large companies in South Africa will perform benchmarking. Due to the difficulty of determining the monetary value of the benefits of a benchmarking project, the extent to which the project met the expectations of the financial manager (or the person nominated by him/her), was used to measure the success of the project. This is explained in the questionnaire (Human, 2000: 124).

Statistical tests performed on the collected data included correlation analysis and t-tests. The outcome of a correlation analysis test is a value between -1 (perfect inverse correlation) and 1 (perfect direct correlation), with 0 indicating no correlation at all. Spearman's product moment coefficient was used to determine whether a statistical relationship exists between each factor and the success of the project. T-tests were applied to indicate whether there is a statistically significant difference in the average values of two groups, and thus whether the finding can be extrapolated to the population.

\section{5}

\section{EMPIRICAL RESULTS}

\subsection{Introduction}

In total 49 (27,5 per cent) questionnaires were returned, of which 22 respondents indicated that they had conducted benchmarking in the past, whilst 24 had never carried out a benchmarking project. Three respondents returned the questionnaires uncompleted with a note that it is not their company's policy to participate in studies like this. One respondent considered the benchmarking project to have been unsuccessful, whilst 15 perceived it as successful and six extremely successful. Companies conducting process and product benchmarking had a higher rate of success than companies performing benchmarking for the mere purpose of collecting information to measure comparative performance. 


\subsection{Summary of the results}

The results of the empirical work can be divided into three categories. Firstly, factors were identified where a statistical relationship between the factor and the success of the project is found (key factors). The second category consists of factors where the results were arranged in such a way that it appears likely that a relationship does exist between the factor and the success of the project for the companies that participated in this study (important factors). Thirdly, certain factors were identified where no meaningful conclusion could be made that a relationship exists between the factor and the success of the project, although most of the companies that achieved success with their project applied these factors (other factors). The results of the empirical work are summarised in Table 1 according to these categories and also classified according to planning, employment of human resources, benchmarking partners, length and scope of the project, ethical and legal aspects as well as completion of the project (Human, 2000: 170-71).

Table 1 - Summary of empirical results

\begin{tabular}{|c|c|c|}
\hline Key factors & Important factors & Other factors \\
\hline \multicolumn{3}{|l|}{ A) Planning } \\
\hline $\begin{array}{l}\text { Conduct a cost-benefit } \\
\text { analysis }\end{array}$ & $\begin{array}{l}\text { Integrated with corporate } \\
\text { strategy }\end{array}$ & $\begin{array}{l}\text { Conduct internal before } \\
\text { external benchmarking }\end{array}$ \\
\hline $\begin{array}{l}\text { Formulate a plan of } \\
\text { implementation }\end{array}$ & $\begin{array}{l}\text { Integration of critical } \\
\text { success factors }\end{array}$ & $\begin{array}{l}\text { Use a questionnaire for } \\
\text { data collection }\end{array}$ \\
\hline & $\begin{array}{l}\text { Study the subject of the } \\
\text { project }\end{array}$ & Conduct a pilot run \\
\hline & $\begin{array}{l}\text { Allocate sufficient } \\
\text { resources }\end{array}$ & $\begin{array}{l}\text { Decide beforehand that } \\
\text { change is required }\end{array}$ \\
\hline & Keep to a timetable & \\
\hline & Stay within a budget & \\
\hline \multicolumn{3}{|c|}{ B) Employment of human resources } \\
\hline & $\begin{array}{l}\text { Involvement of senior } \\
\text { management }\end{array}$ & \\
\hline & $\begin{array}{l}\text { Involvement of people } \\
\text { with prior experience of } \\
\text { benchmarking }\end{array}$ & \\
\hline
\end{tabular}


Table 1 continued

\begin{tabular}{|c|c|c|}
\hline Key factors & Important factors & Other factors \\
\hline & $\begin{array}{l}\text { Involvement of external } \\
\text { consultants }\end{array}$ & \\
\hline & Sufficient training & \\
\hline & $\begin{array}{l}\text { Encouragement of } \\
\text { employee inputs }\end{array}$ & \\
\hline \multicolumn{3}{|c|}{ C) Benchmarking partners } \\
\hline $\begin{array}{l}\text { Partners of comparable } \\
\text { size }\end{array}$ & & $\begin{array}{l}\text { Choose mix of direct and } \\
\text { non-direct competitors }\end{array}$ \\
\hline At least four partners & & $\begin{array}{l}\text { Choose mainly South } \\
\text { African partners }\end{array}$ \\
\hline \multicolumn{3}{|l|}{$\begin{array}{l}\text { Partners from other } \\
\text { Industries }\end{array}$} \\
\hline \multicolumn{3}{|c|}{ D) Length and scope of the project } \\
\hline $\begin{array}{l}\text { Limit the length of the } \\
\text { project }\end{array}$ & Limit scope of the project & \\
\hline \multicolumn{3}{|c|}{ E) Ethical and legal aspects } \\
\hline $\begin{array}{l}\text { Consider ethical and } \\
\text { legal aspects }\end{array}$ & $\begin{array}{l}\text { Choose trustworthy } \\
\text { partners }\end{array}$ & $\begin{array}{l}\text { Sign a confidentiality } \\
\text { agreement }\end{array}$ \\
\hline \multicolumn{3}{|l|}{$\begin{array}{l}\text { Abide by a code of } \\
\text { conduct }\end{array}$} \\
\hline \multicolumn{3}{|l|}{ F) Completion } \\
\hline & $\begin{array}{l}\text { Inform employees of the } \\
\text { results of the project }\end{array}$ & Compile a final report \\
\hline
\end{tabular}

\subsection{Discussion of the key factors}

As indicated above, some of the factors show a statistically significant relationship with the success of a benchmarking project. This includes the costbenefit analysis where all the respondents with extremely successful projects and 67 per cent of the respondents with successful projects performed a costbenefit analysis before embarking on the project. The only respondent with an unsuccessful project did not carry out such an analysis. The relationship between the cost-benefit analysis and success might be ascribed to the fact that a costbenefit analysis can aid organisations in determining in advance whether a project will be in the long-term interest of the company. Thus avoiding investments where the expected costs exceed the expected benefits (Human, 2000: 172). 
All the respondents with extremely successful projects and 93 per cent of the respondents with successful projects prepared a formal plan to implement improvements, prior to launching the project. The respondent with the unsuccessful project again did not formulate such a plan. The results of the ttests indicate that the difference in the average values of the success between the two groups is statistically significant, thus implying a better chance of success if a formal plan is formulated. The best explanation for this probably lies in the fact that there is a risk that improvements will never be implemented if they are not formalised in a plan of action which is followed up by the relevant people within the company (Human, 2000: 173).

The t-tests indicated that benchmarking projects with partners that are smaller or of similar size are more likely to succeed than projects with bigger partners, where 64 per cent of the respondents conducted benchmarking with companies of similar size, 13 per cent with smaller companies and 23 per cent with bigger companies. This tendency might be ascribed to the greater comparability of information between companies of similar size or the possibility that information was not normalised correctly to provide for differences between partners (Human, 2000: 180).

It was possible to prove a positive statistical correlation between the number of benchmarking partners and the success of the project. This means that projects with more partners were generally more successful than those with fewer partners. The optimum number of partners proved to be four. Where companies had more benchmarking partners they were less successful. When a certain stage is reached, the additional processing costs of information outweigh the benefits of increased comparative information, which resembles the law of diminishing returns (Human, 2000: 174).

Scores between 1 and 4 were allocated to indicate the success of a project, where 1 indicates complete failure and 4 an extremely successful project. The average score for the success of projects where all the partners were from the same industry was 3.1 , versus 3.5 where partners from other industries were also included in the projects. The results of the t-tests indicate that this difference in the measured average value for success is statistically significant. The best performers are thus not necessarily operating in the same industry as the company that initiated the project, and a search for the best performers across industries could therefore result in more successful projects (Human, 2000: 175).

An inverse statistical correlation was found between the length of the project and its success. This means that the longer it takes to complete the project, the lower the probability of success. The longer the project runs the higher are the 
costs incurred and the less relevant are its recommendations (Human, 2000: 175).

The results of the t-tests indicated that the success of benchmarking projects was statistically significantly higher when the ethical issues were increasingly taken into consideration. Moreover, the success of benchmarking projects was statistically significantly higher where it was agreed with partners to abide by a code of conduct. It was also possible to prove a positive statistical correlation between the extent to which legal aspects were considered and the success of a project. It seems as if the respondents are in fact aware of the negative implications of ignoring the ethical and legal aspects of benchmarking (Human, 2000: 175).

\section{CONCLUSIONS}

The purpose of this study was to identify which factors have the greatest influence on the success of benchmarking. These factors were identified in the literature and tested among listed South African manufacturing companies.

It appears as if listed South African manufacturing companies achieve a high degree of success with their benchmarking projects. Ninety five per cent of respondents experienced their latest benchmarking project to have been successful, whilst none of the respondents indicated that their most recently completed project was a complete failure (Human, 2000: 179).

The study reveals that benchmarking projects at mostly South African companies of similar size were the most successful, which indicates that the comparability of information is an important consideration. It is however possible that information collected from larger, international companies was not normalised correctly in order to reflect the unique circumstances of the company that initiated the project. Another finding is that the optimum number of benchmarking partners is four. This might be ascribed to the law of diminishing returns, where increased processing costs outweigh the advantages of more information.

\section{REFERENCES}

1 ANDERSEN, B. \& PETTERSEN, P.G. (1996) The Benchmarking Handbook, Chapman \& Hall, London.

2 The Benchmarking Portfolio, Volume Four (TBP) (1997) Strategic Direction Publishers Limited, Uster-Zurich. 
3 BENDELL, T.; BOULTER, L. \& KELLY, J. (1993) Benchmarking for Competitive Advantage, Pitman Publishing, London.

4 BOGAN, C.E. \& ENGLISH, M.J. (1994) Benchmarking for Best Practices, McGraw-Hill Incorporated, New York.

5 ELNATHAN, D.; LIN, T.W. \& YOUNG, S.M. (1996) Benchmarking and Management Accounting: A framework for research", Journal of Management Accounting Research, 8: 37-54.

6 HUMAN, J.S. (2000) "Die Faktore wat Bydra tot die Sukses van Normering", Unpublished Masters dissertation, University of Pretoria.

7 KARLÖF, B. \& ÖSTBLOM, S. (1993) Benchmarking - A Signpost to Excellence in Quality and Productivity, John Wiley \& Sons, Chichester.

8 LINCOLN, S. \& PRICE, A. (1996) "What Benchmarking Books Don't Tell You", Quality Progress, March: 33-6.

9 MANSELL, A. (1997) The Benchmarking Portfolio, Volume One, Strategic Direction Publishers Limited, Uster-Zurich.

10 MAXON, J. \& TREFTY, B. (1997) The Benchmarking Portfolio, Volume One, Strategic Direction Publishers Limited, Uster-Zurich.

11 MILLER, J.G., DE MEYER, A. \& NAKANE, J. (1992) Benchmarking Global Manufacturing, IRWIN, Illinois.

12 RANDALL, N.H.I. (1995) "Benchmarking - A Manufacturing Perspective", Unpublished Masters Dissertation, University of the Witwatersrand, Johannesburg.

13 SCHEFFLER, S. (1997) The Benchmarking Portfolio, Volume One, Strategic Direction Publishers Limited, Uster-Zurich.

14 SPENDOLINI, M.J. (1992) The Benchmarking Book, AMACOM: New York.

15 THOR, C.G. (1995) Practical Benchmarking for Mutual Improvement, Productivity Press, Portland.

16 ZAIRI, M. \& LEONARD, P. (1994) Practical Benchmarking: The Complete Guide, Chapman \& Hall, London. 